\title{
CLINICAL SIGNIFICANCE OF TISSUE DOPPLER IMAGING IN CHRONIC CHAGAS DISEASE
}

\author{
Tomás Cianciulli ${ }^{1}$, María Saccheri ${ }^{2}$, Alonso Papantoniou ${ }^{3}$, Nilda Prado ${ }^{1}$, Adelina Riarte ${ }^{4}$, \\ Ricardo Mendez ${ }^{1}$, Javier Clerici ${ }^{1}$, Martín Beck ${ }^{1}$, Jorge Lax ${ }^{1}$, and Juan Gagliardi ${ }^{1}$ \\ ${ }^{1}$ Hospital del Gobierno de la Ciudad de Buenos Aires "Dr. Cosme Argerich" \\ ${ }^{2}$ Hospital "Dr. Cosme Argerich" \\ ${ }^{3}$ Hospital Argerich \\ ${ }^{4}$ Instituto Nacional de Parasitologia "Dr. Fatala Chaben"
}

April 27, 2020

\begin{abstract}
Introduction: Chagas disease is one of the main diseases in Latin America and heart involvement is its main characteristics, and the main cause of death. The aim of this study is to evaluate if there is any parameter of Doppler Tissue Imaging (DTI) which can be used as a predictor for later events in chronic Chagas disease. Methods: we analyses DTI variables of 543 patients with chronic Chagas disease for the evaluation of predicting factors of events. Major adverse cardiovascular events (MACE) were considered as stroke, heart failure resistant to treatment, sustained ventricular tachycardia, implantable cardioverter-defibrillator, sudden death, and cardiovascular death. The following findings were also included in total evens: heart failure, bradycardia, ventricular arrhythmia, new conduction system abnormalities and new echocardiographic abnormalities. Multivariate analysis with logistic regression was used in order to assess the Doppler and DTI parameters predicting events. Variables with a p-value [?] 0.10 in the univariate analysis were included in the multivariate analysis. Results: In patients with chronic Chagas disease, the analysis of DTI parameters showed that S' wave and E' wave of the lateral wall of the left ventricle were significant predictors of MACE (OR: 0.83; 95\% CI: 0.71-0.96; p value: 0.015 and OR: 0.80; 95\% CI: 0.66-0.98; p value: 0.031, respectively). Conclusions: This study found that patients with chronic Chagas disease who had events showed significantly lower parameters in the DTI. What is more, this study showed that even lower DTI parameters are significant predictors of events.
\end{abstract}

Hosted file Main Document.doc available at https://authorea.com/users/315154/articles/445541-clinicalsignificance-of-tissue-doppler-imaging-in-chronic-chagas-disease 

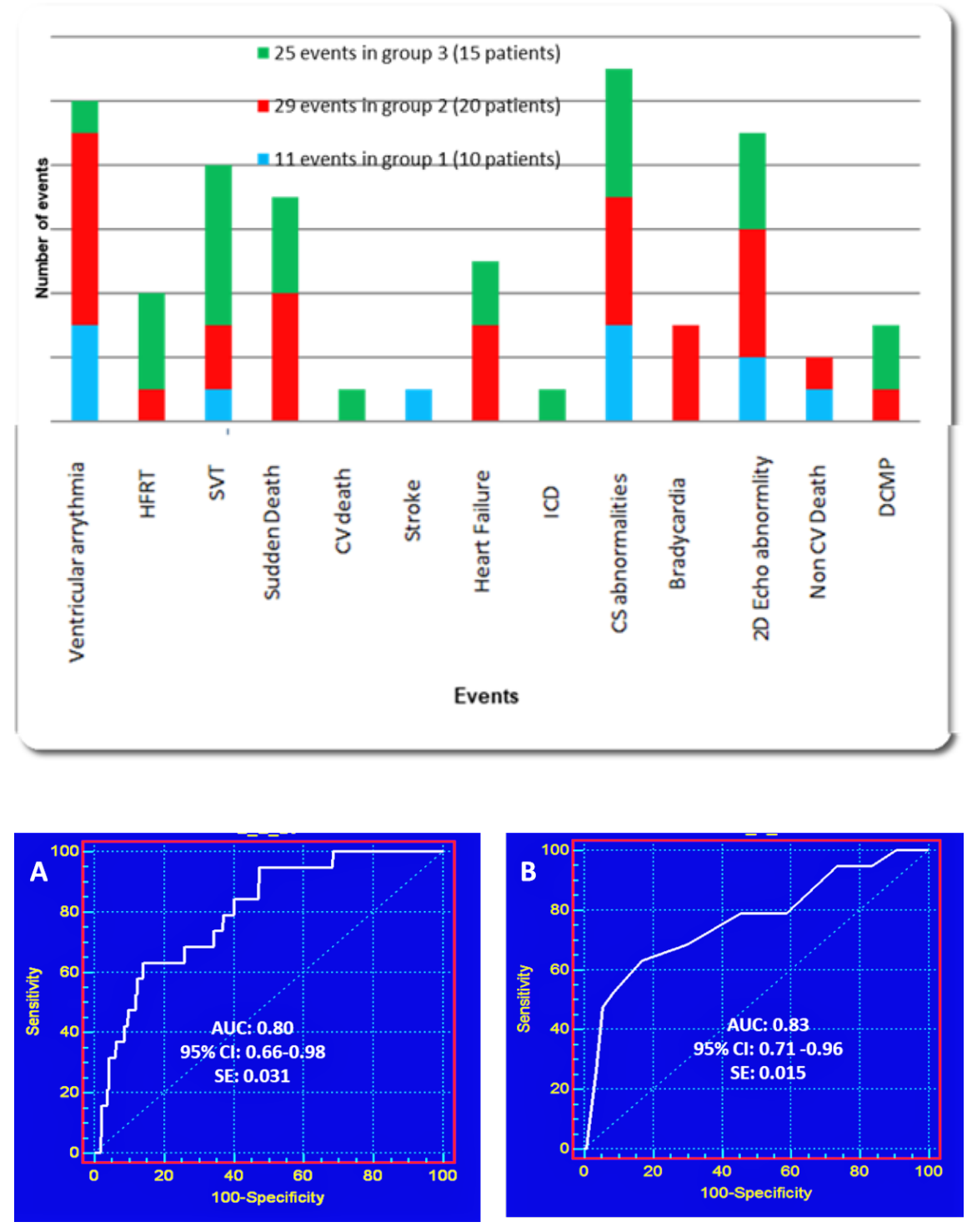